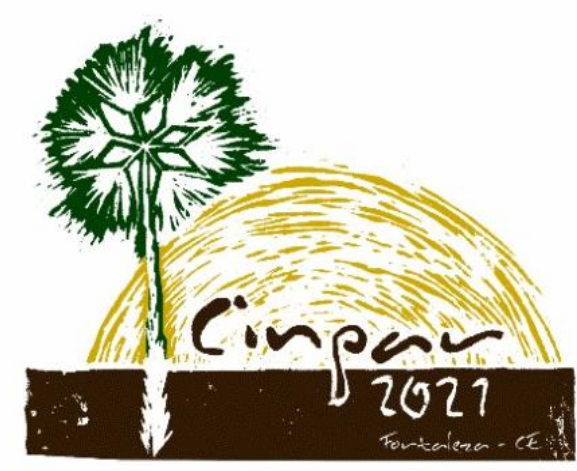

XVII Congresso Internacional sobre Patologia e

Reabilitação das Construções

XVII Congreso Internacional sobre Patología y Rehabilitación de las Construcciones

XVII International Conference on Pathology and Constructions Rehabilitation

FORTALEZA (Brasil), 3 a 5 de junho de 2021

https://doi.org/10.4322/CINPAR.2021.151

\title{
Análise de Danos em Edificações Lindeiras a Área de Desmonte de Rocha: Estudo de Caso de uma Mineiradora Anônima no Brasil
}

\section{Damage Analysis in Buildings Neighboring Rock Blasting Areas: Case Study of an Anonymous Miner in Brazil}

\author{
Marcus Vinícius Fernandes GROSSI ${ }^{1}$
}

${ }^{1}$ Fernandes \& Grossi Engenheiros Associados, São Paulo, Brasil, marcus@fernandesgrossi.com.br

\begin{abstract}
Resumo: Imóveis lindeiros a uma mineiradora situada na região sudeste do Brasil, apresentaram quadro fissuratório em diversas paredes, cuja suspeita dos usuários era de vibração decorrente das atividades de mineração próxima. Este trabalho tem como objetivo realizar o diagnóstico do quadro fissuratório das edificações para definição das possíveis causas e responsáveis para realização do reparo dos danos. 0 estudo foi realizado por meio de inspeção sensorial em campo, medições de vibração do solo com sismógrafo, cálculo de propagação de vibração dos desmontes de rocha e consulta a referências bibliográficas. A partir da análise dos resultados, foi possível concluir que: (a) a maioria das fissuras constatadas estavam dentro da tolerância dimensional das normas técnicas brasileiras, não trazendo prejuízos ao desempenho das edificações; (b) existem diversas causas prováveis para os quadros fissuratório observados, podendo estar relacionado com movimentação do solo, ou das fundações, por falta ou erro no dimensionamento das fundações etc.; (c) todas as vibrações decorrentes das atividades de mineração medidas em campo estavam dentro dos limites aceitáveis da ABNT NBR 9653 (2018); (d) todas as vibrações teóricas, calculadas com base na lei da atenuação, ficaram dentro dos limites aceitáveis da ABNT NBR 9653 (2018). Portanto, fica demonstrado que existem diversas causas que explicam as fissuras identificadas nos imóveis em análise, e mesmo que as vibrações geradas pelas atividades de desmonte tenham gerado ou aumentado alguma das fissuras destes imóveis, estas podem ter aparecido por deficiência construtiva dos imóveis. Então, objetivamente, as atividades de mineração em estudo não são responsáveis pelas fissuras nos imóves lindeiros, visto que as vibrações geradas estão dentro dos limites normativos. Todavia, tal consideração levanta uma eventual necessidade de discução sobre os limites de vibração da ABNT NBR 9653 (2018), visto que podem não garantir a integridade de edificações mais antigas e frágeis.
\end{abstract}

Palavras-chave: Vibração; Fissuras; Mineração; Desmonte de Rocha; Patologia de Construção.

\section{Introdução}

Ao contrário de outras atividades industriais, na mineração, a definição da localização de uma mina é condicionada pela existência e localização do minério, não seguindo apenas fatores de mercado, mas principalmente a geologia, o que acaba muitas vezes fazendo com que algum empreendimento de mineração tenha que estabelecer-se próximo de zonas urbanas, de estruturas ou obras civis e mesmo de áreas de proteção ambiental (SILVA, 2019), podendo ser uma fonte de perturbação para a população e para o meio ambiente, gerando inúmeros impactos, sendo o mais lembrado pela população, os oriundos do uso de explosivos (DORNELES, 2013) Os principais impactos decorrentes do uso de explosivos são: ultralançamento de rocha, poeira, gases, vibração e ruído. De um modo geral, estes dois últimos fenômenos são os que 
acabam tornando os efeitos do uso de explosivos mais notados pelas populações do entorno, potencialmente causando um clima de hostilidade entre mineradora, população e órgãos públicos de fiscalização (DORNELES, 2013).

Neste contexto, este trabalho vem apresentar um estudo realizado em imóveis lindeiros a uma mineiradora situada na região sudeste do Brasil, que apresentaram quadro fissuratório em diversas paredes, cuja suspeita dos usuários era de vibração decorrente das atividades de mineração próxima, onde objetivou-se analisar se o quadro fissuratório reclamado pelo usuários das edificações lindeiras à mineradora eram decorrentes das vibrações dos desmontes de rocha.

\section{Método de inspeção}

Para análise do quadro fissuratório das edificações realizou-se: (a) levantamento do histórico por meio de entrevista com os usuários e funcionários da mineiradora, coletando a data de identificação das anomalias, os dados e datas das atividades de desmonte com explosivos; (b) inspeção sensorial nos imóveis, para análise das manifestações patológicas; (c) medição de vibração do solo durante as atividades de explosão; (d) cálculo de propagação de vibração dos desmontes de rocha de desmontes antigos, para observar se algum gerou vibrações nocivas; (e) comparação dos resultados de vibração com os limites da ABNT NBR 9653 (2018).

\subsection{Medição da vibração do solo}

A medição de vibração do solo foi feita por meio de sismógrafo da marca Vibracord modelo Gaia com resposta em frequência $2-250 \mathrm{~Hz}$ e $1-315 \mathrm{~Hz}$, com precisão de $0,01 \mathrm{~mm} / \mathrm{s}$ atendendo aos requisitos da DIN 45669 .

\section{Apresentação dos dados}

Foram identificadas diversos tipos de causas de fissuras, como recalque, flexão, retração e movimentação térmica, muitas delas fissuras capilares, ou seja, com espessura média de 0,1 a 0,2 mm, em pontos localizados, de pequenas extensões. As que foram objeto de análise foram as mais relevantes, ou seja, que possuiam aberturas maiores e em extensões maiores conforme Figura 1.

Os usuários dos imóveis não souberam definir de maneira exata quais fissuras seriam supostamente decorrentes da atividade mineração, o que levanta a hipótese de que as fissuras poderiam já existir e só foram percebidas depois da maior permanência em sua residência, devido à quarentena de COVID-19, e começar a sentir as vibrações das explosões.

A idade aparente das construções era de 15 a 25 anos, e segundo relatos do proprietário, os imóveis não possuiam projetos executivos e registros de acompanhamento de execução por profissional habilitado, tendo algumas sofrido alterações e reformas, sem qualquer plano de reforma, ou documento que demonstre o dimensionamento e especificação adequados dos elementos estruturais e de vedação.
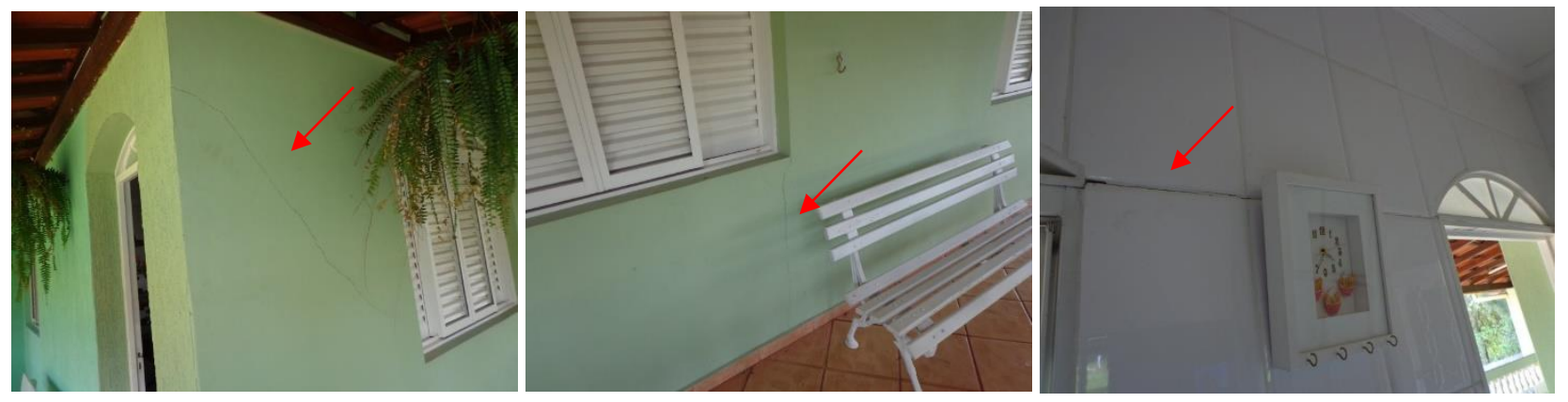

Figura 1 - Exemplo de alguns fissuras constatadas nas inspeções em campo 


\section{Diagnóstico}

\subsection{Classificação das fissuras}

De modo geral, entende-se que fissuras são anomalias praticamente inevitáveis em edificações devido ao comportamento de seus materiais constituintes, e também, por:

a) a grande quantidade de solicitações externas (umidade, temperatura, peso próprio, peso dos móveis e pessoas, impactos, vento etc.);

b) a heterogeneidade dos materiais;

c) a grande quantidade de vinculações entre elementos;

d) o comportamento plástico da maioria dos materiais de construção, principalmente os cimentícios.

Desta forma, a análise das fissuras foi triada pelos critérios a seguir, principalmente segundo a espessura (abertura), comprimento e quantidade, que podem indicar a gravidade do problema e até mesmo auxiliar na identificação da causa.

A ABNT NBR 15575-4 (2013) traz método de análise de fissuração em vedações verticais, conforme descrito no Quadro 1, sendo aceitável fissuras de $10,0 \mathrm{~cm} / \mathrm{m}^{2}$ em ambientes internos, e fissuras não visíveis a $1,0 \mathrm{~m}$ de distância a 250 lux (o que equivale a uma fissura de 0,1 a 0,2 $\mathrm{mm}$ de espessura).

Quadro 1 - Critérios de aceitação para fissuração em vedações verticais (ABNT NBR 15575-4, 2013)

\begin{tabular}{|c|c|c|}
\hline Elemento & Método & Critério \\
\hline \multirow[b]{2}{*}{$\begin{array}{l}\text { Vedação vertical interna, } \\
\text { ou face interna de } \\
\text { vedação vertical externa }\end{array}$} & \multirow[b]{2}{*}{$\begin{array}{l}\text { Inspeção visual (a } 1 \mathrm{~m} \text { da superfície } \\
\text { do elemento, em um cone visual de } \\
60 \text { o, sob iluminação de } 250 \text { lux) }\end{array}$} & - Não apresentar fissuras \\
\hline & & $\begin{array}{l}\text { - } \begin{array}{l}\text { Fissuração que não ultrapasse } 0,1 \\
\mathrm{~m} / \mathrm{m}^{2} \text { (referente à área total das } \\
\text { paredes do ambiente) }\end{array}\end{array}$ \\
\hline $\begin{array}{l}\text { Vedação vertical externa } \\
\text { (fachada) }\end{array}$ & $\begin{array}{l}\text { Inspeção visual (a } 1 \mathrm{~m} \text { da superfície } \\
\text { do elemento, em um cone visual de } \\
60 \text { o, sob iluminação natural em dia } \\
\text { sem nebulosidade) }\end{array}$ & - Não apresentar fissuras \\
\hline
\end{tabular}

A ABNT NBR 6118 (2014) traz critério de aceitabilidade de fissuras em estruturas de concreto armado em função da abertura, conforme descrito no Quadro 2, sendo aceitável fissuras de 0,2 a 0,4 mm de espessura (abertura), a depender da classe de agressividade do meio.

Quadro 2 - Exigências de durabilidade relacionadas à fissuração e à proteção da armadura em função da CAA (Adaptado de ABNT NBR 6118, 2014, p. 80)

\begin{tabular}{|l|c|c|}
\hline $\begin{array}{c}\text { Tipo de concreto } \\
\text { estrutural }\end{array}$ & $\begin{array}{c}\text { Classe de agressividade ambiental e } \\
\text { tipo de protensão }\end{array}$ & $\begin{array}{c}\text { Abertura característica de fissuras na } \\
\text { superfície do concreto }\left(\mathbf{w}_{\mathbf{k}}\right)\end{array}$ \\
\hline Concreto simples & CAA I a IV & Não há \\
\hline \multirow{3}{*}{ Concreto armado } & CAA I & $\leq 0,4 \mathrm{~mm}$ \\
\cline { 2 - 3 } & CAA II e III & $\leq 0,3 \mathrm{~mm}$ \\
\cline { 2 - 3 } & CAA IV & $\leq 0,2 \mathrm{~mm}$ \\
\hline
\end{tabular}

O BRE (1981) define o nível de dano em função da abertura da fissura, conforme Quadro 3, sendo que "para a maioria dos casos, as categorias 0,1 e 2 representam os danos estéticos; as categorias 3 e 4 representam os danos de utilização e a categoria 5 representa os danos de estabilidade".

Desta forma, pode-se classificar que a maioria das fissuras identificadas nos imóveis estavam dentro da aceitabilidade sensorial prevista na ABNT NBR 15575-4 (2013), na ABNT NBR 6118 (2014) e BRE (1981), tendo sido descartadas das análises. 
Quadro 3 - Classificação de fissuras em parede (BRE, 1981)

\begin{tabular}{|c|c|c|}
\hline Categoria do dano & Nível do dano & $\begin{array}{c}\text { Largura da abertura } \\
(\mathbf{m m})\end{array}$ \\
\hline 0 & Negligenciável & $<0,1$ \\
\hline 1 & Muito pequeno & 0,1 a 1 \\
\hline 2 & Pequeno & 1 a 5 \\
\hline 3 & Moderado & 5 a 15 \\
\hline 4 & Severo & 15 a 25 \\
\hline 5 & Muito severo & $>25$ \\
\hline
\end{tabular}

\subsection{Morfologia das fissuras}

As fissuras relevantes, objeto de análise, eram normalmente inclinadas, em diagonal, nos elementos de alvenaria, o que indicam recalque ou flexão dos elementos de apoio.

A sintomatologia, ou morfologia dos quadros fissuratório observados podem estar associados a causas ilustradas em Figura 5 a Figura 8.

Assim sendo, as hipóteses de causas para essas movimentações geradoras de fissuras são:
a) Vibração do solo - atividade de mineração;
b) Vibração do solo - tráfego de veículos;
c) Recalque por sobrecarga nos elementos de fundação;
d) Recalque por movimentação do solo;
e) Sobrecarga dos elementos de vedação.

\subsection{1 - Vibração do solo - atividade de mineração}

Os efeitos de vibração podem gerar fissuras em edificações. Segundo relatos dos usuários, a vibração é percebida sensorialmente quando das explosões da mineração.

Segundo a ABNT NBR 9653 (2018) para análise dos riscos de ocorrência de danos induzidos por vibrações é preciso levar em consideração a magnitude de frequência e velocidade de partícula de pico. Desta forma, entende-se que mesmo havendo vibração, está possui limites aceitáveis, os quais não danificariam edificações construídas corretamente.

Na Figura 2 observa-se o limite de velocidade de partícula, a partir do qual podem ocorrer danos, inicia-se em $15 \mathrm{~mm} / \mathrm{s}$ para frequências de $4 \mathrm{~Hz}$ a $15 \mathrm{~Hz}$ e cresce de acordo com as faixas de frequências até o limite de $50 \mathrm{~mm} / \mathrm{s}$ para frequências acima de $40 \mathrm{~Hz}$.

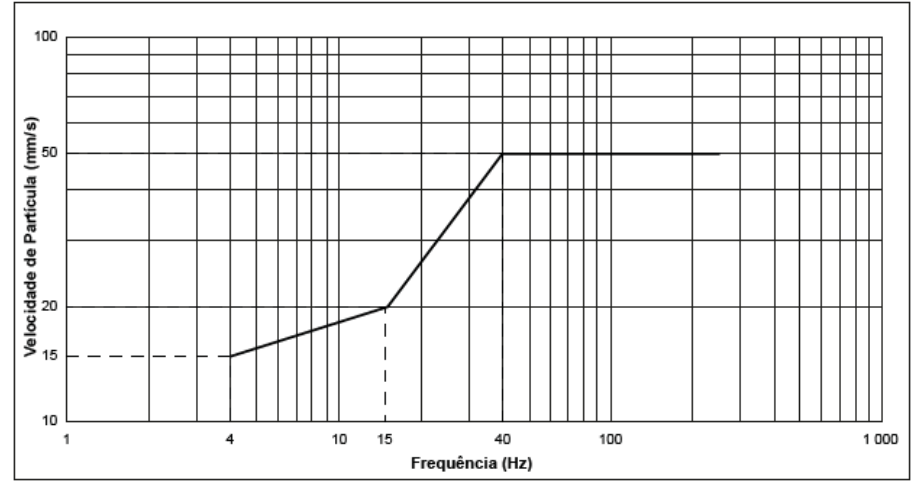

Figura 2 - Representação gráfica dos limites de velocidade de vibração de partícula de pico por faixas de frequência (ABNT NBR 9653, 2018) 
Foram coletados os registros de detonação de junho/2020 a novembro/2020 medidos por empresa terceirizada pela mineiradora. A oscilação do chão foi medida por sismógrafo e transformada em velocidade de vibração de partícula ( $\mathrm{mm} / \mathrm{s}$ ) em três componentes ( $\mathrm{x}$, y e z).

Os dados apresentados na Figura 3 são as velocidades de pico em cada uma das componentes. Nota-se que todos os pontos medidos estão dentro dos limites aceitáveis pela ABNT NBR 9653 (2018).

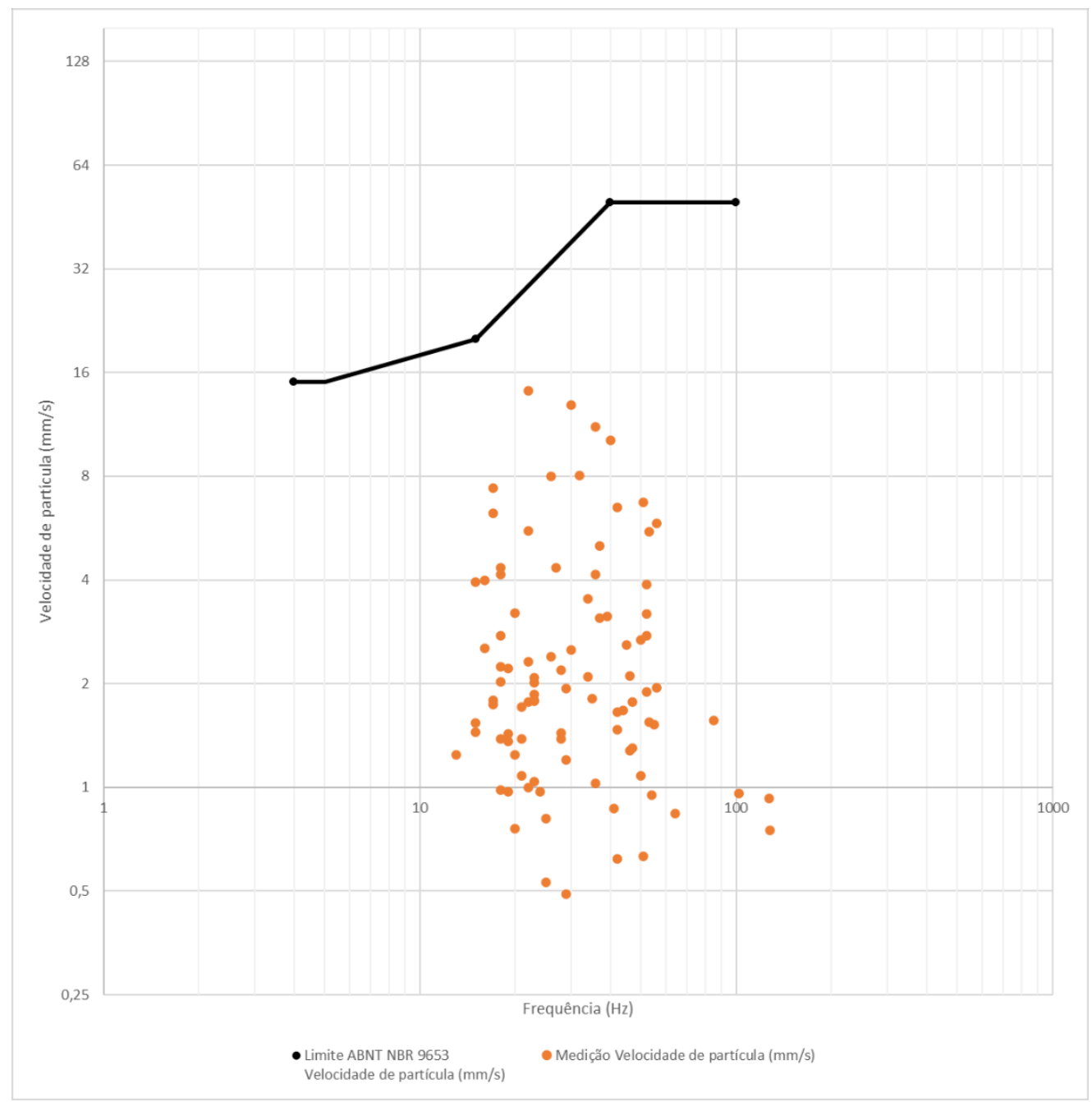

Figura 3 - Dados coletados de velocidade de vibração de partícula de pico por faixas de frequência em comparação com os limites da ABNT NBR 9653:2018

\subsubsection{1 - Determinação da equação de atenuação}

Para verificar se os desmontes de rocha realizados desde o início das reclamações dos usuário, tinham gerado vibrações nocivas, utilizou-se a equação de atenuação de ondas sísmicas, determinando a vibração pela carga máxima de explosivos, utilizando-se a velocidade de vibração de pico de partícula. Segundo Silva (2019), estudos mostram que uma relação empírica entre a velocidade de partícula $V$, carga máxima $Q$, e a distância D, que pode ser representada pela Equação 1.

$$
V=k\left(\frac{D}{\sqrt{Q}}\right)^{-m}
$$

$\mathrm{Na}$ Equação 1 as constantes $\mathrm{k}$ e $\mathrm{m}$ variam de acordo com as condições geológicas, geotécnicas e consequentemente físicas de um maciço estão estritamente relacionadas a suas propriedades de atenuação de vibrações, de forma a produzir trens de ondas vibratórias característicos ao longo da trajetória de propagação. 
A Figura 4 mostra a regressão linear realizada em dados de monitoramento sismográfico realizados em diversos desmontes de rocha, tratados para que tivessem um coeficiente de determinação $\left(r^{2}\right)$ superior a 0,7 , que resultou na Equação 2 de lei de atenuação do terreno em análise.

$$
V=1893,3\left(\frac{D}{\sqrt{Q}}\right)^{-1,695}
$$

Com base na Equação 2 verificou-se o nível de vibração de pico em todos os imóveis em todos os desmontes de rocha computados desde 24/06/2020, data de início das reclamações, onde obteve-se os dados dispostos no Quadro 4, não tendo nenhum valor acima de $15 \mathrm{~mm} / \mathrm{s}$, portanto, todos os dados dentro dos limites permitidos pela ABNT NBR 9653 (2018).

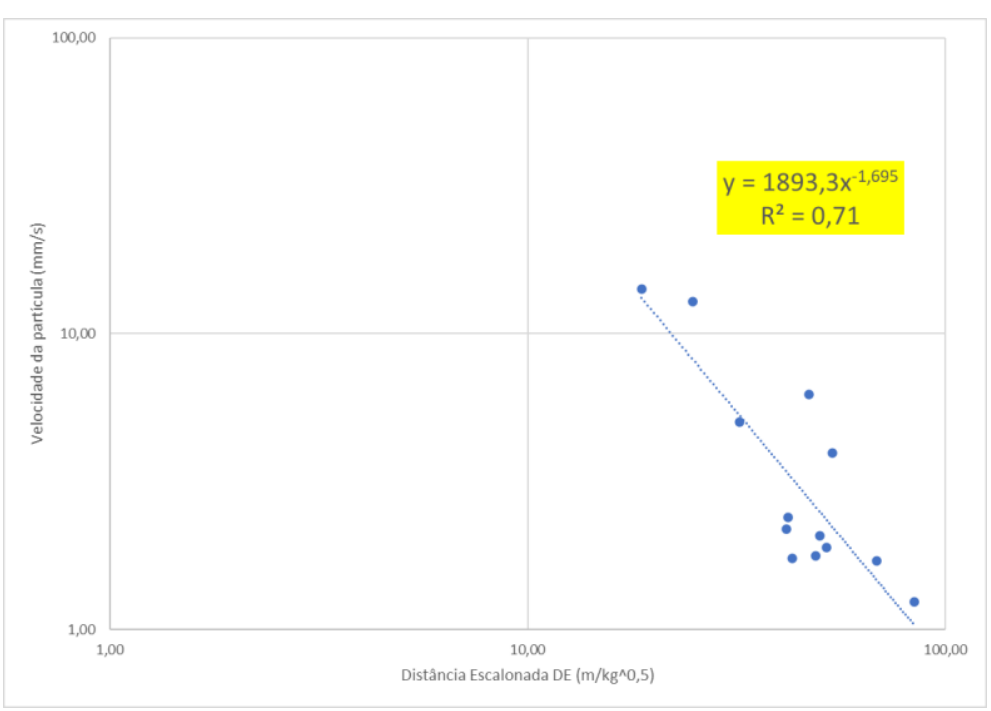

Figura 4 - Gráfico da lei de atenuação da velocidade de vibração

Quadro 4 - Análise de vibração teórica nos imóveis em análise pela lei da atenuação

\begin{tabular}{|c|c|c|c|c|c|c|c|c|}
\hline \multirow{2}{*}{ Fogo } & \multirow{2}{*}{ Data } & \multicolumn{3}{|c|}{ Distância $\mathbf{( m )}$} & Carga (kg) & \multicolumn{3}{c|}{ Velocidade de vibração (mm/s) } \\
\cline { 3 - 8 } & & Imóvel 01 & Imóvel 03 & Imóvel 06 & & Imóvel 01 & Imóvel 03 & Imóvel 06 \\
\hline $\mathbf{1}$ & $24 / 06 / 2020$ & 500 & 850 & 1250 & 94,6 & 2,38 & 0,97 & 0,50 \\
\hline $\mathbf{2}$ & $21 / 07 / 2020$ & 515 & 880 & 1280 & 188,0 & 4,06 & 0,06 & 0,00 \\
\hline $\mathbf{3}$ & $06 / 08 / 2020$ & 810 & 800 & 1165 & 110,0 & 1,20 & 0,03 & 0,00 \\
\hline $\mathbf{4}$ & $26 / 08 / 2020$ & 575 & 715 & 1120 & 110,0 & 2,14 & 0,05 & 0,00 \\
\hline $\mathbf{5}$ & $26 / 08 / 2020$ & 715 & 560 & 960 & 110,0 & 1,48 & 0,06 & 0,00 \\
\hline $\mathbf{6}$ & $22 / 09 / 2020$ & 575 & 750 & 1150 & 128,0 & 2,43 & 0,05 & 0,00 \\
\hline $\mathbf{7}$ & $22 / 09 / 2020$ & 550 & 715 & 1115 & 117,0 & 2,43 & 0,06 & 0,00 \\
\hline $\mathbf{8}$ & $14 / 10 / 2020$ & 500 & 770 & 1180 & 49,3 & 1,37 & 0,03 & 0,00 \\
\hline $\mathbf{9}$ & $14 / 10 / 2020$ & 550 & 680 & 1100 & 196,0 & 3,76 & 0,09 & 0,00 \\
\hline $\mathbf{1 0}$ & $10 / 11 / 2020$ & 730 & 540 & 950 & 112,0 & 1,45 & 0,06 & 0,00 \\
\hline $\mathbf{1 1}$ & $10 / 11 / 2020$ & 570 & 680 & 1100 & 156,0 & 2,92 & 0,07 & 0,00 \\
\hline
\end{tabular}

4.2.2 - Vibração do solo - atividade de mineração

Os efeitos de vibração por tráfego de veículos podem gerar fissuras em edificações, em especial no imóvel 01, devido à proximidade da rodovia.

Segundo Hunaidi (2000) a tendência da vibração oriunda de veículos pesados é a geração de ondas no solo entre $1 \mathrm{~Hz}$ e $80 \mathrm{~Hz}$ com uma velocidade da partícula de $0,2 \mathrm{~mm} / \mathrm{s}$ a $50 \mathrm{~mm} / \mathrm{s}$, dependendo do tipo e das condições da pista, do peso e velocidade do veículo, e de seu sistema de amortecimento, podendo gerar fissuras em edificações.

Tal hipótese de causa não pode ser eliminada pelo fato de não ter sido monitorado as vibrações de tráfego de veículos. 
4.2.3 - Recalque por sobrecarga da fundação

A sobrecarga nas fundações pode se dar por mal dimensionamento, má execução dos elementos, carga excessiva colocada na edificação etc. gerando movimentações destes elementos, que transferem esforços às alvenarias, que por não ser resistente a esforços de tração, fissuram conforme Figura 5 a Figura 7.

Tal hipótese de causa não pode ser eliminada diante as grandes incertezas e falta de registros de correto dimensionamento e execução dos elementos de fundação.

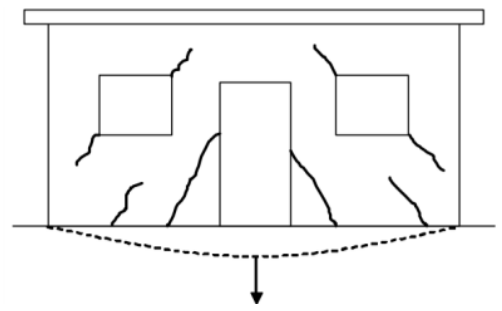

Figura 5 - Deformação côncava de parede autoportante e seus efeitos (URIEL ORTIZ, 1983)

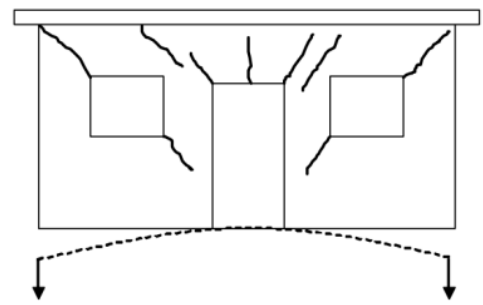

Figura 6 - Deformação convexa de parede autoportante e seus efeitos (URIEL ORTIZ, 1983)

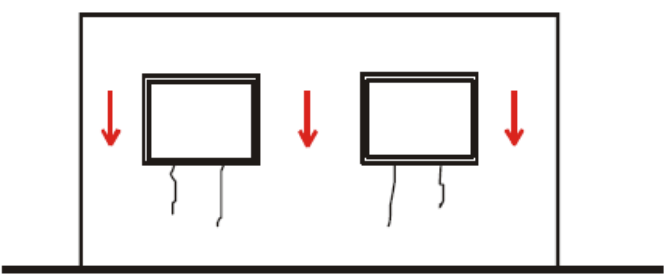

Figura 7 - Fissuras verticais em peitoris por flexão negativa (DUARTE, 1998)

\subsection{4 - Recalque por movimentação do solo}

O recalque por movimentação do solo pode ocorrer por falha de investigação geotécnica, má compactação do solo, erosão do solo, ruptura de tubulações enterradas, mal dimensionamento dos elementos de fundação, e rebaixamento natural ou artificial do lençol freático.

A alvenaria por não ser resistente a esforços de tração, fissuram conforme Figura 5 a Figura 7.

Porém, não é possível associar o quadro fissuratório das edificações em análise, sem a análise dos projetos e registros de investigação geotécnica. Considerando que existem diversas causas para esta movimentação.

Portanto, tal hipótese de causa não pode ser eliminada diante as grandes incertezas e falta de registros.

\subsection{5 - Sobrecarga dos elementos de vedação}

A sobrecarga nos elementos de vedação pode ocorrer por má qualidade dos blocos ou argamassa de assentamento, assim como, falta de execução de reforços nos vãos de janela e porta (verga e contraverga) fissurando conforme Figura 8.

Portanto, tal hipótese de causa não pode ser eliminada diante as grandes incertezas e falta de registros. 


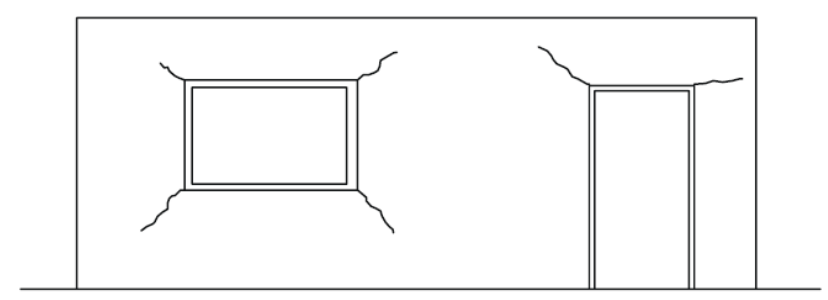

Figura 8 - Fissuras reais em torno de aberturas por sobrecarga (THOMAZ, 1989)

\section{Conclusões}

O objetivo deste trabalho foi analisar se o quadro fissuratório reclamado pelo usuários das edificações lindeiras à mineradora, situada na região sudeste do Brasil, eram decorrentes das vibrações dos desmontes de rocha, por meio de inspeção sensorial em campo, medições de vibração do solo com sismógrafo, cálculo de propagação de vibração dos desmontes de rocha. De acordo com a apresetançãos dos dados e diagóstico conclui-se que:

a) A maioria das fissuras constatadas estavam dentro da tolerância dimensional das normas técnicas brasileiras, não trazendo prejuízos ao desempenho das edificações;

b) Existem diversas causas prováveis para os quadros fissuratório observados, podendo estar relacionado com movimentação do solo, ou das fundações, por falta ou erro no dimensionamento das fundações, ausência ou falhas nas investigações geotécnicas, colocação de carga excessiva sobre às fundações, variação do nível do lençol freático etc., principalmente pelo fato das edificações não possuírem projetos básicos, ou registros de responsável técnico habilitado;

c) Todas as vibrações decorrentes das atividades de mineração medidas em campo estavam dentro dos limites aceitáveis da ABNT NBR 9653 (2018);

d) Todas as vibrações teóricas calculadas com base na lei da atenuação ficaram dentro dos limites aceitáveis da ABNT NBR 9653 (2018);

Portanto, fica demonstrado que existem diversas causas que explicam as fissuras identificadas nos imóveis em análise, e mesmo que as vibrações geradas pelas atividades de desmonte tenham gerado ou aumentado alguma das fissuras destes imóveis, estas podem ter aparecido por deficiência construtiva dos imóveis. Então, objetivamente, as atividades de mineração em estudo não são responsáveis pelas fissuras nos imóves lindeiros, visto que as vibrações geradas estão dentro dos limites normativos. Todavia, tal consideração levanta uma eventual necessidade de discução sobre os limites de vibração da ABNT NBR 9653 (2018), visto que podem não garantir a integridade de edificações mais antigas e frágeis.

\section{Referências Bibliográficas}

Associação Brasileira de Normas Técnicas (2014). NBR 6118: Projeto de estruturas de concreto Procedimento. Rio de Janeiro, 2014.

(2018). NBR 9653: Guia para avaliação dos efeitos provocados pelo uso de explosivos nas minerações em áreas urbanas. Rio de Janeiro, 2018.

(2013). NBR 15575-4: Edificações habitacionais — Desempenho - Parte 4: Requisitos para os sistemas de vedações verticais internas e externas - SVVIE. Rio de Janeiro, 2013.

Building Research Establishment Digest (1981). Assessment of damage in low-rise buildings: with particular reference to progressive foundation movement. Garston, n.251, 1981

Dorneles, Felipe Tavares (2013). Controle e previsão de vibrações e ruídos gerados por desmonte de rochas com explosivos. TCC. Universidade Federal dos Pampas, Caçapava do Sul-RS.

Duarte, Ronaldo Bastos (1998). Fissuras em Alvenarias: Causas Principais, Medidas. Preventivas e Técnicas de Recuperação. Porto Alegre: CIENTEC, 1998. 45 p

Ortiz, A. U. (1983). Patologia de las cimentaciones. Informe de La Construcción, Madri, v. 35, p.5-35, 1983.

Silva, Valdir Costa (2019). Desmonte de rochas. São Paulo: Oficina de Textos, 2019.

Thomaz, Ercio (1989). Trincas em edifícios: causas, prevenção e recuperação. São Paulo: PINI, 1989. 